\title{
MÉTODO ECONÓMICO Y EFICIENTE PARA LA CUANTIFICACIÓN COLORIMÉTRICA DE LISINA EN GRANO DE MAÍZ
}

\section{INEXPENSIVE AND EFFICIENT COLORIMETRIC METHOD FOR THE LYSINE CUANTIFICATION ON WHOLE MAIZE GRAIN}

\author{
Luis A. Galicia-Flores, Catalina Islas-Caballero, \\ Aldo Rosales-Nolasco y Natalia Palacios-Rojas*
}

Programa Global de Maíz, Centro Internacional de Mejoramiento de Maíz y Trigo (CIMMYT). km 45 vía México-Veracruz. 56130, Texcoco, Estado de México, México. Tel. +52 (595) 9521900 Ext.1112

*Autor para correspondencia (n.palacios@cgiar.org)

\section{RESUMEN}

Los maíces (Zea Mays L.) de alta calidad proteínica (ACP) tienen mayor contenido de lisina y triptófano, dos aminoácidos esenciales que normalmente están presentes en bajas cantidades en el grano de maíz. La metodología colorimétrica que se usa actualmente para monitorear el contenido de lisina en el grano de maíz es costosa y poco reproducible. El presente trabajo es una modificación a la metodología para la determinación colorimétrica de lisina en grano completo de maíz. Se hizo una reducción de reactivos costosos como el acetato de etilo, reducción de riesgos al personal que se encarga de desarrollar este análisis por la disminución en la emisión de residuos contaminantes, y reducción de pasos para desarrollar la curva de calibración, lo cual aumenta la capacidad de análisis por día. La metodología descrita se validó por comparación con la metodología colorimétrica de referencia y con NIR, y se obtuvieron coeficientes de determinación $\left(R^{2}\right)$ de 0.97 y de 0.85 , respectivamente. El método desarrollado es económico, preciso y rápido, y puede ser usado para la determinación de lisina en un gran número de muestras durante los programas de mejoramiento.

Palabras clave: Método colorimétrico, modificación, maíz de alta calidad proteínica (ACP), lisina.

\section{SUMMARY}

Quality protein maize (QPM, Zea mays L.) has higher content of lysine and tryptophan, two essential amino acids usually present in low quantities in maize kernels. The colorimetric method used currently to measure lysine in maize is time consuming and poorly reproducible. This paper describes a modification to the methodology for colorimetric determination of lysine in whole grains of maize. Reduction of costly reagents, risks for operators and reduction in the number of steps to prepare the calibration curve are the main modifications done to the previous protocol and which largely improve the efficiency and cost of the analysis. The alternative methodology was validated by comparison with the reference colorimetric method and NIR, obtaining high coefficients of determination $\left(R^{2}\right) 0.97$ and 0.85 , respectively. The modified method is inexpensive, reliable and fast, and can be used for the determination of lysine in large number of samples for breeding programs.
Index words: Colorimetric method, modification, Quality protein maize (QPM), lysine.

\section{INTRODUCCIÓN}

El maíz (Zea mays L.) juega un papel importante en la nutrición humana y animal. El grano de maíz aporta entre 15 y $56 \%$ de la ingesta calórica diaria de la población en alrededor de 25 países en vías de desarrollo, particularmente en África y América Latina (Atlin et al., 2011). El grano de maíz normalmente es deficiente en los aminoácidos esenciales tales como lisina, triptófano y metionina, debido principalmente a la proporción alta de prolaminas como proteínas de almacenamiento que carecen de dichos aminoácidos (Prasanna et al., 2001; Sofi et al., 2009).

El término QPM (Quality Maize Protein o ACP, alta calidad proteínica), se refiere al maíz que tiene el gen opaco 2 (o2) junto con genes modificadores, cuya acción origina un maíz con mayor contenido de lisina y triptófano y un endospermo relativamente duro, que lo hace resistente a las plagas durante el almacenamiento. El maíz ACP no es un producto de eventos transgénicos y tiene el mismo aspecto y se desarrolla de la misma forma que el maíz convencional (normal); puede ser diferenciado únicamente por medio de análisis de laboratorio que cuantifican su contenido de lisina y triptófano (Sierra-Macías et al., 2004; Krivanek et al., 2007). El consumo de maíz ACP contribuiría al aseguramiento de la cantidad de proteína e ingesta de aminoácidos esenciales requeridos por el ser humano (Nuss y Tanumihardjo, 2011).

De esta forma, se hace necesaria la cuantificación de lisina y triptófano durante las etapas del mejoramiento 
de los maíces ACP. Debido a que estos aminoácidos guardan una proporción aproximadamente constante de 4:1, normalmente se da seguimiento sólo al contenido de triptófano como parámetro para la evaluación de la calidad nutricional de la proteína de maíz (Vivek et al., 2008). Por su parte, el análisis de lisina usado para apoyar programas de mejoramiento de maíces ACP (Villegas et al., (1984), presenta características que limitan su implementación: a) La hidrólisis enzimática se debe realizar en tubos de ensayo porque se usan $100 \mathrm{mg}$ de muestra previamente acondicionada y el volumen de la solución de extracción es de $5 \mathrm{~mL}$; b) En la reacción colorimétrica por cada muestra a analizar se requieren $15 \mathrm{~mL}$ de acetato de etilo como solución de lavado, volumen que prolonga el tiempo del análisis puesto que se debe pipetear repetidamente para remover el solvente antes de hacer la lectura en el espectrofotómetro; c) Elaboración de la curva de calibración con numerosas diluciones, que provocan que se prolongue el tiempo requerido en esta fase y que aumentan el error durante su preparación.

La cuantificación se basa en la reacción entre el compuesto 2-cloro-3, 5-dinitripiridina y el grupo $\xi$-amino de lisina, después de haber bloqueado con cobre los grupo $\alpha$-amino de los aminoácidos y de los péptidos de bajo peso molecular presentes en el hidrolizado proteínico. El complejo $\xi$-dinitropiridil-lisina que se forma es soluble en agua pero insoluble en acetato de etilo, lo que permite remover los demás compuestos formados durante la reacción, y además eliminar el exceso del reactivo 2-cloro-3, 5-dinitripiridina (Tsai et al., 1972).

El objetivo del presente trabajo fue modificar la metodología para que la cuantificación de lisina sea un análisis útil para apoyar los programas de mejoramiento. Con base en el método de Villegas et al. (1984), se optimizó el desarrollo de las curvas de calibración, se redujeron los volúmenes para la reacción y se implementó el uso de microplacas, todo lo cual reduce tiempo de trabajo ya que permite analizar hasta 36 muestras por duplicado, en una sola lectura.

\section{MATERIALES Y MÉTODOS Reactivos y soluciones}

El fosfato de sodio dibásico (Cat. 3828), borato de sodio (Cat. 3568), carbonato de sodio (Cat. 3602), bicarbonato de sodio (Cat. 3506-05), fosfato de sodio tribásico (Cat. 3836), fosfato de potasio monobásico (Cat. 3246) y el cloruro cúprico (Cat. 1792-01) se adquirieron con la empresa J. T. Baker (Phillipsburg, NJ, USA). El ácido clorhídrico (Cat. 1.00317.2500) y el acetato de etilo (Cat. EX0240-5) se obtuvieron de la empresa Merck KGaA (Darmastadt, Germany). Con la empresa Sigma-Aldrich (St. Luis, MO,
USA) se adquirieron el 2-cloro-3, 5-dinitripiridina (Cat. 22,404-9) y la mezcla de aminoácidos: cistina, metionina, prolina, histidina, alanina, isoleucina, treonina, tirosina, glicina, fenilalanina, valina, arginina, serina, ácido aspártico, leucina y acido glutámico (Cat. LAA21-1KT). La papaína purificada 0.32 MCU (Milk Cloth Units) Proteoferm ${ }^{\circledR}$ fue adquirida con la empresa Mixim (Naucalpan, Estado de México, México). La lisina (L-Lisina monoclorhidrato, Cat. 6364) fue adquirida con la empresa Nutritional Biochemicals Corp. (Cleveland Ohio, USA).

Las soluciones de papaína $\left(4 \mathrm{mg} \mathrm{mL}^{-1}\right.$ y $\left.5 \mathrm{mg} \mathrm{mL}^{-1}\right)$ se prepararon diariamente a temperatura ambiente con una solución amortiguadora de fosfatos $0.03 \mathrm{M}$ con $\mathrm{pH} 7.4$ (mezcla de fosfato de sodio dibásico y fosfato de potasio monobásico). Diariamente se preparó la suspensión de cobre al disolver $2.8 \mathrm{~g}$ de cloruro cúprico en $100 \mathrm{~mL}$ de gua y $13.6 \mathrm{~g}$ de fosfato de sodio tribásico en $200 \mathrm{~mL}$ de agua. Se mezclaron ambas soluciones, se centrifugaron a $800 \mathrm{x} g$ durante $5 \mathrm{~min}$ (aprox. $37.5 \mathrm{~mL}$ en cada tubo) y se descartó el sobrenadante. El precipitado se lavó tres veces con 15 $\mathrm{mL}$ (por tubo) de solución amortiguadora de boratos 0.05 $\mathrm{M}$ con $\mathrm{pH}$ 9, y al final se resuspendió el precipitado con 80 $\mathrm{mL}$ de la misma solución.

La solución de 2-cloro-3,5-dinitropiridina a $3 \%(\mathrm{p} / \mathrm{v})$ en metanol, se preparó minutos antes de ser utilizada. La solución de aminoácidos se preparó mediante la dilución $100 \mathrm{mg}$ de la mezcla de aminoácidos en $10 \mathrm{~mL}$ de una solución amortiguadora de carbonatos $0.05 \mathrm{M}$ con pH 9. La solución concentrada de lisina se utilizó como estándar y se preparó utilizando la solución reguladora de carbonatos a una concentración de $1000 \mu \mathrm{g} \mathrm{mL}$.

\section{Muestras de maíz}

Se utilizaron maíces (no-ACP y ACP) del programa de mejoramiento del CIMMYT (Centro Internacional del Mejoramiento del Maíz y Trigo). La metodología fue validada en 70 muestras de maíz ACP y 70 muestras maíz no-ACP.

\section{Procedimiento de extracción}

Se molieron 30 semillas por cada muestra de maíz, en un molino Cyclotec 1093 (manufacturado por Foss Tecator ${ }^{\circledR}$, Hoganas, Sweden) con una malla de acero inoxidable de $0.5 \mathrm{~mm}$. La harina obtenida se desengrasó con hexano en un extractor intermitente Soxhlet durante $6 \mathrm{~h}$ continuas. Posteriormente se evaporó el excedente de hexano. En microtubos se digirieron $30 \mathrm{mg}$ de harina desengrasada con $1.55 \mathrm{~mL}$ de la solución de papaína $\left(4 \mathrm{mg} \mathrm{mL}^{-1}\right)$, verificando la ausencia de partículas de harina adheridas a la paredes del microtubo y sin estar en contacto con la solución de 
extracción. La solución de papaína sin muestra fue utilizada como blanco. Las muestras se incubaron a $64{ }^{\circ} \mathrm{C}$ por $16 \mathrm{~h}$, con agitación por lo menos dos veces durante la primera hora de incubación. Se aseguró que los microtubos estuvieran perfectamente cerrados para evitar la evaporación de la solución. Una vez completada la incubación, los extractos se enfriaron a temperatura ambiente y se centrifugaron a $20160 \mathrm{x} g$ por $5 \mathrm{~min}$, para así agregar un sobrenadante libre de partículas de harina.

\section{Reacción colorimétrica}

Se transfirieron $500 \mu \mathrm{L}$ del hidrolizado (sobrenadante) a un nuevo microtubo de $1.5 \mathrm{~mL}$ y se adicionaron 250 $\mu \mathrm{L}$ de la solución amortiguadora de carbonatos y 250 $\mu \mathrm{L}$ de suspensión de cobre. Se agitaron manualmente durante $5 \mathrm{~min}$ y se centrifugaron a $1333 \mathrm{x} g$ por $5 \mathrm{~min}$. Se transfirieron $125 \mu \mathrm{L}$ de sobrenadante a un microtubo nuevo de $2 \mathrm{~mL}$ y se adicionaron $12.5 \mu \mathrm{L}$ de reactivo 2-cloro-3, 5-dinitropiridina. Después de una fuerte agitación en vórtex, las muestras se protegieron de la luz y se incubaron a temperatura ambiente durante $2 \mathrm{~h}$ con agitación cada 30 min; después de la incubación se les agregó $625 \mu \mathrm{L}$ de ácido clorhídrico $1.2 \mathrm{~N}$ y se agitaron nuevamente hasta homogenizar. Posteriormente, se adicionaron $650 \mu \mathrm{L}$ de acetato de etilo y la solución se mezcló por inversión de los tubos por 10 veces; luego se dejaron en reposo para permitir la formación de dos fases, y se eliminó el sobrenadante resultante. El lavado con acetato de etilo se repitió dos veces más, pero en la última repetición, después de mezclar la solución, los tubos se centrifugaron a 1333 x $g$ por 5 min para asegurar la separación de las dos fases formadas y la remoción del acetato de etilo. Los tubos con la tapa abierta se colocaron por 5 min en la campana de extracción para asegurar la eliminación de cualquier remanente de acetato de etilo, y finalmente se transfirió una alícuota de $200 \mu \mathrm{L}$ a microplacas de 96 pocillos. La lectura se llevó a cabo en un lector de microplacas ( $\mu$ Quant (MQX200), BioTek $\left.{ }^{\circledR}\right)$ para determinar la densidad óptica (DO) a $390 \mathrm{~nm}$.

\section{Curva de calibración}

Semanalmente se preparó una solución concentrada $\left(1000 \mu \mathrm{g} \mathrm{mL}^{-1}\right)$ de lisina con una solución amortiguadora de carbonatos $0.05 \mathrm{M}$ con $\mathrm{pH}$ 9. La solución concentrada de lisina se almacenó a $4{ }^{\circ} \mathrm{C}$. La curva de calibración se desarrolló diariamente en un rango de 50 a $200 \mu \mathrm{g} \mathrm{mL} \mathrm{m}^{-1}$ de lisina, para lo cual se diluyeron distintos volúmenes de la solución concentrada en la solución amortiguadora de carbonatos y la solución de papaína $\left(5 \mathrm{mg} \mathrm{mL}^{-1}\right)$, como se muestra en el Cuadro 1.

Posteriormente, en tubos de vidrio se hizo la etapa inicial de la reacción colorimétrica, con una alícuota de $1 \mathrm{~mL}$
Cuadro 1. Curva de calibración para la cuantificación de lisina.

\begin{tabular}{ccccc}
\hline $\begin{array}{c}\text { Tubo de solución } \\
\text { concentrada de lisina } \\
\left(1000 \mu \mathrm{mL}^{-1}\right)\end{array}$ & $\begin{array}{c}\text { mL de solución } \\
\text { amortiguadora de } \\
\text { carbonatos }\end{array}$ & $\begin{array}{c}\mathrm{mL} \text { de solución } \\
\text { de papaína } \\
\left(5 \mathrm{mg} \mathrm{mL}^{-1}\right)\end{array}$ & $\begin{array}{c}\text { Concentración } \\
\text { final de lisina } \\
\left(\mu \mathrm{gL}^{-1}\right)\end{array}$ \\
\hline 1 & 0 & 2.0 & 8 & 0 \\
2 & 0.5 & 1.5 & 8 & 50 \\
3 & 1.0 & 1.0 & 8 & 100 \\
4 & 1.5 & 0.5 & 8 & 150 \\
5 & 2.0 & 0 & 8 & 200 \\
\hline
\end{tabular}

de cada dilución y $0.5 \mathrm{~mL}$ de la solución de carbonatos que contiene la mezcla de aminoácidos y $0.5 \mathrm{~mL}$ de la suspensión de cobre. La adición de solución de papaína con concentración de $5 \mathrm{mg} \mathrm{mL}^{-1}$ y la mezcla de aminoácidos, tiene por objeto garantizar la acción bloqueadora del cobre y evitar sobreestimaciones. El resto de la reacción colorimétrica se hizo como se describió previamente.

\section{Validación del método modificado para la cuantificación de lisina}

Para verificar la precisión y exactitud de la modificación propuesta, 140 muestras se analizaron también por el método colorimétrico descrito por Villegas et al. (1984) y por NIR (espectrofotometría en el infrarrojo cercano).

\section{Cálculos y análisis estadístico}

El porcentaje de lisina se obtuvo al multiplicar la DO corregida $\left(\mathrm{DO}_{390 \mathrm{~nm}}\right.$ muestra $\left.-\mathrm{DO}_{390 \mathrm{~nm} \text { promedio de los blancos de papana }}\right)$ a $390 \mathrm{~nm}$ por el cociente volumen del hidrolizado/(pendiente de la curva estándar x peso de la muestra). Se utilizó un diseño completamente al azar con dos repeticiones. Se efectuó un análisis de varianza y comparación de medias con el método de Tukey $(\alpha=0.05)$ con el programa SAS 9.2 (SAS Institute, 2008).

\section{RESULTADOS Y DISCUSIÓN}

Por lo general, en los programas de fitomejoramiento de maíces ACP únicamente se monitorea el contenido de triptófano, debido a la alta correlación que existe entre el contenido de triptófano y el de lisina, principalmente en programas de conversión de líneas normales a ACP. Otras razones para monitorear únicamente el contenido de triptófano en programas de mejoramiento de maíces ACP son el costo y el tiempo requerido por el análisis de lisina con la metodología propuesta por Villegas et al. (1984), según Vivek et al. (2008). Sin embargo, la modificación realizada en este trabajo ofrece la posibilidad de realizar ambos análisis (lisina y triptófano) a un menor costo y en un mayor número de muestras, con más rapidez del análisis y con un método reproducible. 
Entre las modificaciones realizadas al método de referencia se incluye la reducción de reactivos de elevado costo, como el acetato de etilo, y reducción de los riesgos al personal que se encarga de desarrollar este análisis debido a la disminución en la emisión de residuos contaminantes. La cantidad de acetato que se requiere para el método aquí propuesto representa solamente $13 \%$ del volumen original. Otra ventaja importante es la reducción de pasos para desarrollar la curva de calibración, lo cual aumenta la capacidad de análisis por día.

El Cuadro 2 muestra el intervalo de valores de la DO para cada una de las concentraciones conocidas evaluadas en las curvas de calibración desarrolladas y leídas en microplaca. Los rangos presentados corresponden a 11 curvas de calibración efectuadas en diferentes días, con un $\mathrm{R}^{2}$ superior a 0.98 en cada curva.

Cuadro 2. Rango de densidad óptica (DO) a $390 \mathrm{~nm}$, de la curva de calibración de lisina.

\begin{tabular}{cccc}
\hline $\begin{array}{c}\text { Concentración } \\
\text { de lisina } \\
\left(\mu \mathrm{g} \mathrm{mL}^{-1}\right)\end{array}$ & $\begin{array}{c}\text { Rango de DO a } \\
390 \mathrm{~nm}\end{array}$ & $\begin{array}{c}\text { Promedio de } \\
\text { DO a 390 nm }\end{array}$ & $\begin{array}{c}\text { Desviación } \\
\text { estándar }\end{array}$ \\
\hline 0 & $0.119-0.148$ & 0.134 & 0.0084 \\
50 & $0.158-0.185$ & 0.175 & 0.0091 \\
100 & $0.209-0.250$ & 0.229 & 0.0154 \\
150 & $0.280-0.289$ & 0.285 & 0.0026 \\
200 & $0.297-0.324$ & 0.313 & 0.0080 \\
\hline
\end{tabular}

Existen otros métodos para la cuantificaron de lisina que se basan en la reacción del ácido 1-sulfónico-2,4,6trinitrobenceno (TNBS) o en la reacción colorimétrica de la nihidrina (Beckwith et al., 1975; Obi, 1982). Sin embargo, éstos presentan algunas desventajas, como requerir un tratamiento previo de la muestra para la remoción de aminoácidos libres o varias filtraciones de soluciones durante el desarrollo del análisis, lo cual demanda más manipulación y tiempo. Se han propuesto también metodologías bacteriológicas para la cuantificación de lisina, pero dado que son métodos semi-cuantitativos dependientes del tiempo de crecimiento de las bacterias, su aplicabilidad en programas de mejoramiento ha sido restringida (Nurit et al., 2009). El método que aquí se propone mantiene un proceso de acondicionamiento de muestras y de hidrólisis enzimática que requieren poca manipulación por parte del personal del laboratorio.

La cromatografía líquida (HPLC) es otra técnica utilizado para la cuantificación de lisina (Paulis et al., 1991). Sin embargo, su elevado costo y tiempo de análisis hace que esta metodología no sea una alternativa para apoyar programas de mejoramiento.

\section{Comparación de dos métodos para la cuantificación de lisina}

La correlación para las 140 muestras analizadas con ambos métodos fue de 0.96 (Figura 1), aunque se observó una menor correlación entre los materiales con contenido de lisina menor a $0.3 \%$ (maíz normal). Según Nurit et al. (2009), este tipo de diferencias son atribuibles a las bajas concentraciones de lisina y a los mayores errores estándar, lo que disminuye la precisión de los valores obtenidos. El valor mínimo detectado con el método modificado es de $0.19 \%$ de lisina en grano completo.

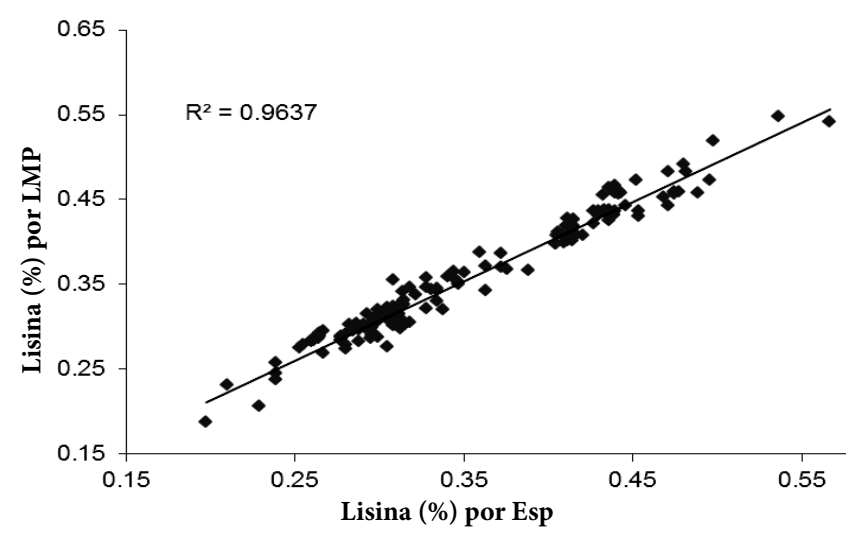

Figura 1. Correlación entre el porcentaje de lisina cuantificado mediante el método en espectrofotómetro (Esp) y la cuantificación en microplaca (LPM) $(\mathrm{n}=140$ muestras).

Con base en la comparación de medias $(\mathrm{P} \leq 0.05)$, los dos métodos evaluados no presentaron diferencia significativa, con medias de porcentaje de lisina de 0.359 y 0.355 para LMP y Esp, respectivamente. Al comparar los datos obtenidos con el método químico modificado y los datos obtenidos por NIR (Modelo Lysun1), la correlación obtenida es de 0.83 (Figura 2), valor similar al que se ha obtenido previamente con dicho modelo y con datos provenientes del método en espectrofotómetro.

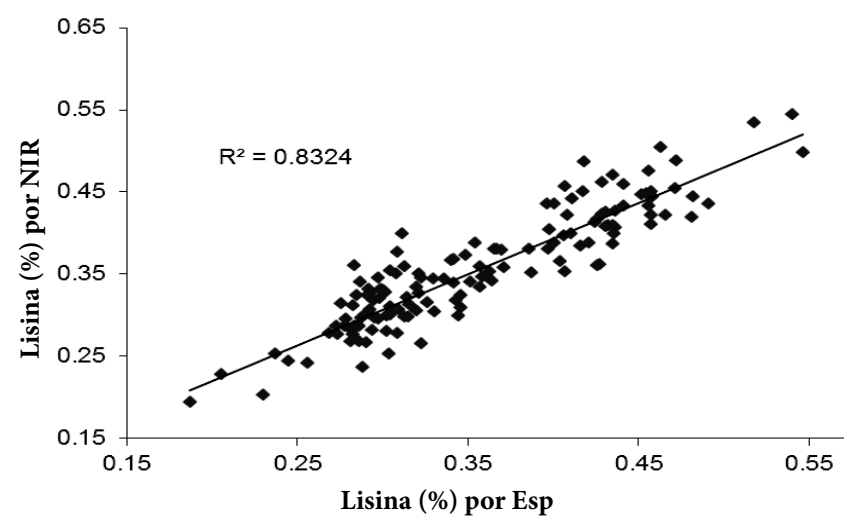

Figura 2. Correlación entre el porcentaje de lisina cuantificado mediante NIR y la cuantificacion en microplaca (LPM) ( $n=140$ muestras). 
Actualmente el análisis de lisina por química húmeda tiene un costo de USD\$ 7.90 por muestra. Con las modificaciones propuestas dicho costo se reduce hasta en $30 \%$. Adicionalmente, con la metodología propuesta, un solo técnico de laboratorio puede analizar hasta 100 muestras por día, mientras que con el método de referencia se requiere el trabajo de dos técnicos por día para analizar igual número de muestras.

El costo del análisis por NIR es de USD \$ 4.3 por muestra y tiene la ventaja de ser una metodología que no involucra tratamiento previo ni extracción de la muestra. No obstante, un equipo NIR es costoso y se deben tener en cuenta los siguientes puntos: 1) Requiere curvas de calibración robustas, desarrolladas con un rango amplio de contenido del analito y diferentes germoplasmas; 2) Transferencia adecuada de curvas de calibración entre equipos distintos, mediante la verificación de la compatibilidad de los programas de cómputo utilizados y de los criterios usados en las ecuaciones generadas.

De acuerdo con los resultados obtenidos con el método descrito, se concluye que es viable su implementación en los programas de mejoramiento de maíces ACP. Dada la simplificación y bajo costo de la metodología descrita, se convierte en una herramienta adecuada para el estudio de la variabilidad del contenido de lisina en maíces criollos o nativos como parte de la caracterización de la diversidad genética del maíz.

\section{BIBLIOGRAFÍA}

Atlin G N, N Palacios, R Babu, B Das, S Twumasi-Afriyie, D K Friesen, H DeGroote, B Vivek, K V Pixley (2011) Quality protein maize: Progress and prospects. Plant Breed. Rev. 34:83-130.
Beckwith A C, J W Paulis, J S Wall (1975) Direct estimation of lysine in corn meals by the ninhydrin color reaction. Agric. Food Chem. 23:194-196.

Krivanek A F, H De Groote, N Gunaratna, A Diallo, D Friesen (2007) Breeding and disseminating quality protein maize (QPM) for Africa. African J. Biotech. 6:312-324.

Nurit E, A Tiessen, K Pixley, N Palacios-Rojas (2009) Reliable and inexpensive colorimetric method for determining protein-bound tryptophan in maize kernels. J. Agri. Food Chem. 57:7233-7238.

Nuss E, S Tanumihardjo (2011) Quality protein maize for Africa: closing the protein inadequacy gap in vulnerable populations. Adv. Nutr. 2: 217-224

Obi I U (1982) Application of the 2, 4, 6-trinitrobenzene-1-sulfonic acid (TNBS) method for determination of available lysine in maize seed. Agric. Biol. Chem. 46:15-20.

Paulis J W, J A Bietz, R J Lambert, E M Villegas (1991) Identification of modified high-lysine maize genotypes by reversed-phase highperformance liquid chromatography. Cereal Chem. 68:361-365.

Prasanna B M, S K Vasal, B Kassahun, N N Singh (2001) Quality protein maize. Curr. Sci. 81:1308-1319.

SAS Institute Inc (2008) Statistical Analysis System (version 9.2). Cary, Noth Carolina, USA.

Sierra-Macías M, A Palafox, O Cano, F Rodríguez, A Espinosa, A Turrent, N Gomez, H Córdova, N Vergara, R Aveldaño, J Sandoval, S Barrón, J Romero, F Caballero, M Gonzalez, E Betanzos (2004) H-553C, híbrido de maíz de calidad proteica para trópico húmedo de México. Rev. Fitotec. Mex. 27:117-119.

Sofi P A, S A Wanil, A G Rather, S H Wani (2009) Review article: Quality protein maize (QPM): Genetic manipulation for the nutritional fortification of maize. J. Plant Breed. Crop Sci. 1:244-253.

Tsai C Y, L W Hansel, O E Nelson (1972) A colorimetric method of screening maize seeds for lysine content. Cereal Chem. 49:572579.

Villegas E, E Ortega, R Bauer (1984) Chemical methods used at CIMMYT for determining protein quality in cereal grains. CIMMYT. Mexico, D. F. 35 p.

Vivek B S, A F Krivanek, N Palacios-Rojas, S Twumasi-Afriyie, A Diallo (2008) Breeding quality protein maize (QPM): Protocols for developing QPM cultivars. CIMMYT. Mexico, D. F. 105 p. 